\title{
Ageing and Health : How far Bangladesh is prepared?
}

\author{
Rowshon AHM
}

Population ageing is a natural phenomenon and is inevitable. In complex ways it changes society and creates challenges and opportunities. On the other hand, older people already make a significant contribution to the society through the formal workforce, informal work and volunteering or within family. Their contribution can be fostered by helping them to maintain good health and by breaking many barriers of their participation in the ongoing process in the society. On the other hand, towards the end of life, many people will face health problems and challenges to their independent lives. World Health Organization has therefore taken the slogan "Ageing and Health" on the world health day 2012 to address these phenomenon in a way that is affordable and sustainable for families and society. Numerous determinants of healthy and active ageing life beyond the health system. Many of which starts to exert their influence at earlier stage of life. Our response, therefore, need to tackle issue across the life course and in many social spheres. But the health sector, too, needs to adapt. In many developing countries including Bangladesh, infectious disease is main barriers of good health as well as of being aged in active form. Overwhelmingly the health challenges in the older age are the consequence of non-communicable disease. We need to develop health systems which can provide the appropriate care that these diseases and their risk factors require.

The global brief takes a fresh look at existing heath data and draws on some exciting new work to help us better understand exactly what these needs are. It identifies action we can take. It si now up to the global community to take up the challenges it identifies and truly add life to our increasing years.

Followings are few key points which should be taken into consideration to face the problem efficiently and effectively:

Population ageing is a global phenomenon that is now occurring fastest in low-and middle-income countries. Population ageing is inextricably linked with socioeconomic development. While ageing presents challenges to society, it also creates many opportunities. Fostering good health in oldie age is central to the global response to population ageing. Poor health in older age is not just a burden for the individual but also for their families and for society as a whole. The poorer the family or the setting the greater the impact.

The main challenges for older people are noncommunicable diseases. The impact of these conditions is two to three times greater for older people in low-and middle-income countries than for people of high- income countries. Current health systems, particularly in low-and middle-income countries, are poorly designed to meet the chronic care needs that arise from this complex burden of disease. Ageing is interrelated with other major global trends such as urbanization, technological change and globalization. Increasing longevity may even lead us to rethink the ways we view "old" itself.

There is no simple "magic bullet" solution to the challenges of population ageing but there are concrete actions that governments and societies can take now. Promoting good health and healthy behaviors at all stages to prevent or delay the development of chronic disease. Minimizing the consequences of chronic disease through early direction and quality care (primacy, long-term and preventive care). Creating physical and social environments that foster the health and participation of older people.

Reinventing ageing- changing social attitudes to encourage the participation of older people. In many ways, population ageing can be viewed as a direct consequence of socioeconomic development. While the experience of each country will vary, the common patterns emerge. As living conditions improve and access to health care providers increases, mortality during childhood and childbirth falls, there is greater likelihood of children to survive and will live longer. As a consequence, adoption of family planning measures increase that lower the number of young people 
while already born people are living more and move to the traditional working ages to reinforce economic growth. But this population bulge eventually moves into older age and if fertility rates remain low (as platitude in many developed and developing countries), the proportion of older people in population increases. These changes dramatically shift population structures from a dominance of younger age groups, to one where all age groups are more equally represented.

Population ageing is taking place in every country, although each country is at a different stage of this transition. These trends are also evident for the oldest age groups; in the middle of the 20th century, there were just 14 million people on the whole planet aged 80 years or above. By 2050 , there will be 100 million living in China alone, and 400 million people in the this age group worldwide.

For countries such as France and Sweden, population ageing has taken many years but for countries that are now experiencing the same transition is taking less time. Thus, while it took more100 years for the share of France's population aged 65 older to increase from $7 \%$ to $14 \%$, countries including Basil, China and Thailand will experience the same demographic shift in just 20 years. This gives them much less time to put in place the infrastructure to address the needs of this older population. Bangladesh is one of the poorest countries of the world, having very high level of unemployment problems and thus failed to utilize young working force for social and economic development. Infrastructure for providing health care services to its people including older people is also not well equipped. On he contrary, by adopting the Millennium Development Goal (MDG) program of United Nations, it became partially successful in achieving four health related parameters (including EPI, MMR,IMR) of 15 points MDG and is awarded by the WHO.

It is reasonable to believe that Bangladesh will have a changed demography of population with higher percentage of young and aged people in a period of time, shorter than that taken by the developed countries. For proper utilization of young working force for social and economic development opportunities for employment will have to be created. At the same time, we will have to develop our infrastructure for providing proper care treatment of aged people who are supposed to contribute in present development of the society and country.

\section{References}

1. The global burden of disease:2004 update, Geneva, World Health Organization, 2008. Available at http.//www.who.int/evidence/bod
2. World development report 2004: equity and development. Washington, DC, World Bank, 2006

3. Global health risks: mortality and burden of disease attributable to selected major risks. Geneva. World Health Organization, 2009

4. World reports on disability. Geneva, World Health Organization, 2011

5. Global population ageing: peril or promise? Geneva, World Economic Forum, 2012 